\title{
Evaluation of Different Thyroid Lesions with Fine Needle Aspiration Cytology and Thyroid Function Tests
}

\author{
Ranabhat $\mathbf{S}^{1^{*}}$, Parajuli $\mathbf{B}^{1}$, Poudel $\mathbf{S}^{1}$, Pun $\mathbf{G}^{1}$ \\ ${ }^{1}$ Lecturer, Department of Pathology, Gandaki Medical College \& Teaching Hospital, Pokhara, Nepal
}

\section{Keywords}

Fine Needle Aspiration Cytology (FNAC), Thyroid Function Test (TFT),

Thyroid lesions.

\section{Corresponding author \\ *Dr. Sunita Ranabhat \\ Lecturer, Department of Pathology \\ Gandaki Medical College \& Teaching \\ Hospital, Pokhara, Nepal \\ Email: sunitaranabhat7@gmail.com}

\begin{abstract}
Introduction: Swelling of the thyroid gland is a commonly encountered clinical problem in all age groups whether benign or malignant. Fine Needle Aspiration Cytology (FNAC) of the thyroid lesions along with hormonal function test helps in the proper preoperative assessment. Ultimately it changes clinical management and improves the patient outcome.
\end{abstract}

Objectives: To describe the cytomorphological features of palpable thyroid nodules using fine needle aspiration cytology (FNAC) along with the assessment of thyroid hormonal status of the patient.

Methods: The study was conducted in the Department of Pathology of Gandaki Medical College and Teaching hospital from January 2017 to December 2017 and included 50 patients with thyroid lesions. Cytological assessment was done using FNAC along with serological assessment of thyroid hormones.

Results: In the study 50 cases of thyroid swelling were included and evaluated by cytological and hormonal analysis which comprises of $10 \%$ males and $90 \%$ females with a with a female to male ratio of 9 :

1. Maximum number of cases was seen in the age range $41-60$ years (46\%), mean age being 44.6 years. The cytological diagnosis comprised colloid goiter (58\%), lymphocytic thyroiditis (16\%), Hashimoto thyroiditis (10\%). Thyroid hormone analysis showed 66\% euthyroid, $22 \%$ hypothyroid and $12 \%$ hyperthyroid.

Conclusions: The study showed that FNAC and TFT profile both are essential for the proper management of thyroid lesions. FNAC along with hormonal analysis helps in proper patient assessment and management.

\section{INTRODUCTION}

Swelling of the thyroid gland is a common manifestation of various diseases of thyroid whether benign or malignant. Although, many are benign but still the reports and study have shown that the prevalence of malignancy among the solitary nodular goiter is about $10 \%$. Among the various types of malignancy of thyroid gland, papillary carcinoma of thyroid is the most common followed by follicular, medullary, anaplastic and lymphoma ${ }^{1}$.

It is said that FNAC of thyroid was introduced in 1950 and has been popular worldwide since $1980^{2}$.

Nowadays FNAC of thyroid is a well-established gold standard procedure performed in outpatient department for the evaluation of diffuse and solitary thyroid swelling. FNAC is a simple, cost effective, readily repeated 
minimally invasive and quick to perform procedure. The main purpose is to reduce unnecessary surgery thereby confirming benign lesions ${ }^{3}$. FNAC is however not without limitation; accuracy is lower in suspicious cytology and in follicular neoplasm.

In thyroid gland follicles are the basic morphological unit. They produce hormones triiodothyronine (T3) and thyroxin (T4) which are in turn regulated by thyroid stimulating hormone produced by anterior pituitary gland $^{4}$. The lesions of thyroid can be categorized in hypothyroid euthyroid or hyperthyroid condition based on the assessment of the level of T3, T4 and TSH.

In the present study, cytomorphological features of thyroid FNAC were evaluated and classified in different categories based on The Bethesda System of Reporting Thyroid Cytology and evaluated with the hormonal status of the concerned patient.

\section{METHODS}

The present study was conducted at the Department of Pathology, Gandaki Medical College and Teaching Hospital, from January 2017 to December 2017. A total 50 cases were analysed during this period. Prior to aspiration a physical examination was done to note the mobility and presence of any cervical lymph node. FNAC was performed using aseptic precaution with nonaspiration or aspiration technique by $23 \mathrm{G}$ needle with $10 \mathrm{ml}$ syringe. In cases of cystic lesion fluid was aspirated first followed by reaspiration from the nodule. In cases when the lesions were invisible USG guided FNAC was performed. One slide was kept in absolute alcohol and others were air dried and stained in Papanicolau and Giemsa stains respectively.

The TFT profile was performed using ELISA kits from Human Gesellschaft fur Biochemica and Diagnostic MbHMaxPlanck-Ring 21, D-6205 Wiesbaden, Germany Serozyme ELISA. The cytomorphological detail, FNAC diagnosis and TFT detail were entered in Microsoft excel 2013 and study variable were statistically analysed by SPSS16.

\section{RESULTS}

The study was conducted in the Gandaki Medical College and Teaching Hospital from January 2017 to December 2017. A total of 50 thyroid swelling were analyzed. In this study the total number of females were 45 (90\%) while males five $(10 \%)$ (Table 1). In this study we found the most of the patients were females and female to male ratio was $9: 1$. The age of the patients in the study ranged from 8 years to 82 years. Maximum number of cases were seen in the age group of 41 - 60 years (46\%) followed by 20 - 40 years (30\%). The Mean age of the patients with thyroid lesions was 44.6 years.

Table 1: Age and gender distribution of patients with palpable thyroid lesions

\begin{tabular}{cccc}
\hline \multirow{2}{*}{ Age group } & \multicolumn{2}{c}{ Sex } & \multirow{2}{*}{ Total } \\
\cline { 2 - 3 } & Females & Males & \\
\hline$<20 y r s$ & 3 & 1 & 4 \\
$21-40 y r s$ & 13 & 2 & 15 \\
$41-60 y r s$ & 21 & 2 & 23 \\
$>$ 61yrs & 8 & 0 & 8 \\
Total & 45 & 5 & 50 \\
\hline
\end{tabular}

FNAC was performed by aspiration and non-aspiration technique on all patients with serological thyroid hormone estimations. Out of 50 cases non-neoplastic lesions were more common accounting 44 cases (88\%) while neoplastic were six cases $(12 \%)$. The cytological diagnosis consisted predominantly of colloid goitre 29 cases $(58 \%)$ followed by lymphocytic thyroiditis eight cases $(16 \%)$ and hashimoto's thyroiditis five cases $(10 \%)$. Other cases included papillary carcinoma of thyroid, subacute thyroiditis, follicular neoplasm and anaplastic carcinoma (Table 2).

Table 2: Distribution of cytological diagnosis in different age group

\begin{tabular}{lcccccccc}
\hline & \multicolumn{7}{c}{ Diagnosis } & \\
\cline { 2 - 7 } Age group & Tolloid & Subacute & Lympho & Hashimoto & Pap & FN & Anaplastic & \\
\hline < 20 yrs & 3 & 0 & 0 & 1 & 0 & 0 & 0 & 4 \\
21 - 40 yrs & 4 & 1 & 4 & 1 & 4 & 1 & 0 & 15 \\
41 - 60 yrs & 15 & 1 & 3 & 3 & 0 & 0 & 1 & 23 \\
$>61$ yrs & 7 & 0 & 1 & 0 & 0 & 0 & 0 & 8 \\
Total & 29 & 2 & 8 & 5 & 4 & 1 & 1 & 50 \\
\hline
\end{tabular}

Thyroid hormone profile was done, which showed 33 cases (66\%) were euthyroid, 11 cases (22\%) were hypothyroid and six cases $(12 \%)$ were hyperthyroid. Out of 29 cases (58\%) of colloid goitre, 23 cases $(79 \%)$ were euthyroid, two cases $(7 \%)$ were hyperthyroid and four cases $(14 \%)$ were hypothyroid. In case of Hashimoto's thyroiditis four cases $(80 \%)$ were hypothyroid and one case $(20 \%)$ was euthyroid. Whereas in lymphocytic thyroiditis four 
cases (50\%) were euthyroid, three cases (38\%) were hypothyroid and one case (12\%) were hyperthyroid. In neoplastic lesion, out of four cases (8\%) of papillary carcinoma of thyroid three cases (75\%) were euthyroid and one case $(25 \%)$ was hyperthyroid. Similarly both follicular neoplasm and anaplastic carcinoma presented with euthyroid (Table 3).

Table 3: TFT analysis in different thyroid lesion

\begin{tabular}{lcccc}
\hline \multirow{2}{*}{ Diagnosis } & \multicolumn{3}{c}{ TFT } & Total \\
\cline { 2 - 4 } & Euthyroid & Hyperthyroid & Hypothyroid & \\
\hline Anaplastic & 1 & 0 & 0 & 1 \\
Colloid & 23 & 2 & 4 & 29 \\
$\begin{array}{l}\text { Follicular } \\
\text { neoplasm }\end{array}$ & 1 & 0 & 0 & 1 \\
$\begin{array}{l}\text { Hashimoto } \\
\text { Lympho }\end{array}$ & 1 & 0 & 4 & 5 \\
$\begin{array}{l}\text { Papillary } \\
\text { carcinoma }\end{array}$ & 3 & 1 & 3 & 8 \\
Subacute & 0 & 2 & 0 & 4 \\
\multicolumn{1}{c}{ Total } & $\mathbf{3 3}$ & $\mathbf{6}$ & $\mathbf{1 1}$ & $\mathbf{5 0}$ \\
\hline
\end{tabular}

In our study, among males the common cause of thyroid swelling was subacute thyroiditis followed by colloid goitre and anaplastic carcinoma. In case of females, common thyroid swelling was due to colloid goitre followed by lymphocytic thyroidits, hashimoto's thyroiditis then papillary carcinoma of thyroid and follicular neoplasm (Table 4).

Table 4: Distribution of cytological diagnosis among gender

\begin{tabular}{|c|c|c|c|c|c|c|c|c|c|}
\hline & \multirow[b]{2}{*}{ Sex } & \multicolumn{7}{|c|}{ Diagnosis } & \multirow[b]{2}{*}{ Total } \\
\hline & & Colloid & $\begin{array}{l}\text { Sub- } \\
\text { acute }\end{array}$ & $\begin{array}{l}\text { Lym- } \\
\text { pho }\end{array}$ & $\begin{array}{l}\text { Hash- } \\
\text { imoto }\end{array}$ & Pap & Fn & $\begin{array}{l}\text { Ana- } \\
\text { plastic }\end{array}$ & \\
\hline \multirow[t]{2}{*}{$\mathrm{F}$} & Count & 28 & 0 & 8 & 5 & 3 & 1 & 0 & 45 \\
\hline & $\begin{array}{l}\% \text { within } \\
\text { Sex }\end{array}$ & $62.2 \%$ & $.0 \%$ & $17.8 \%$ & $11.1 \%$ & $6.7 \%$ & $2.2 \%$ & $.0 \%$ & $100.0 \%$ \\
\hline \multirow[t]{2}{*}{ M } & Count & 1 & 2 & 0 & 0 & 1 & 0 & 1 & 5 \\
\hline & $\begin{array}{l}\% \text { within } \\
\text { Sex }\end{array}$ & $20.0 \%$ & $40.0 \%$ & $.0 \%$ & $.0 \%$ & $20.0 \%$ & $.0 \%$ & $20.0 \%$ & $100.0 \%$ \\
\hline \multirow[t]{2}{*}{ Total } & Count & 29 & 2 & 8 & 5 & 4 & 1 & 1 & 50 \\
\hline & $\begin{array}{l}\% \text { within } \\
\text { Sex }\end{array}$ & $58.0 \%$ & $4.0 \%$ & $16.0 \%$ & $10.0 \%$ & $8.0 \%$ & $2.0 \%$ & $2.0 \%$ & $100.0 \%$ \\
\hline
\end{tabular}

Fig 1: Papillary structures in papillary carcinoma of thyroid (Giemsa 100X)

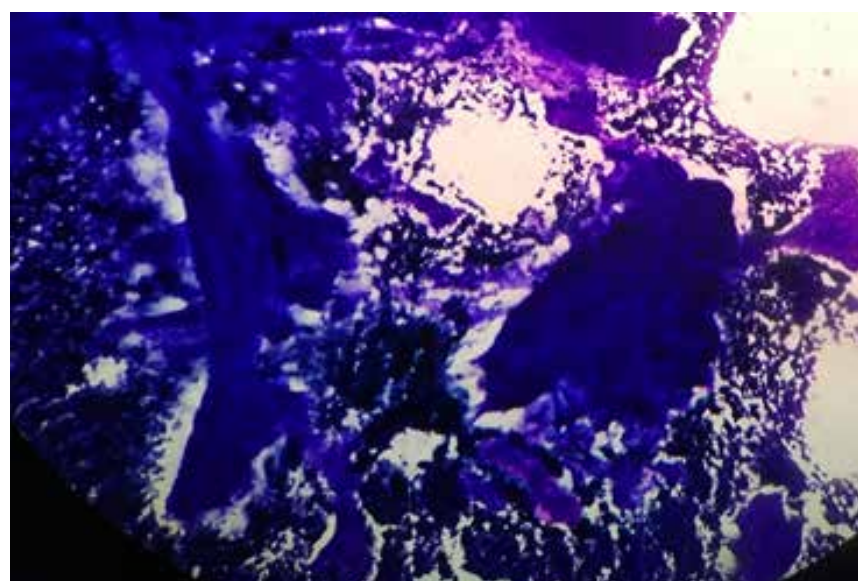

Fig 2: Intranuclear cytoplasmic inclusion in PTC (Giemsa 1000X) Papillary carcinoma of thyoid

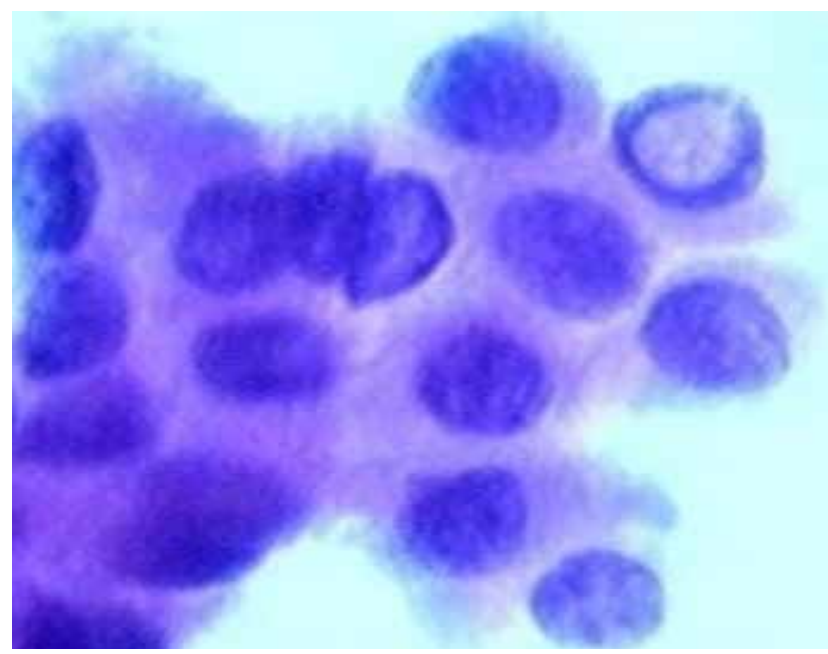

Fig 3: Lymphocytes impinging into follicles along with hurthle cells in Hashimoto thyroiditis (Giemsa 400x)

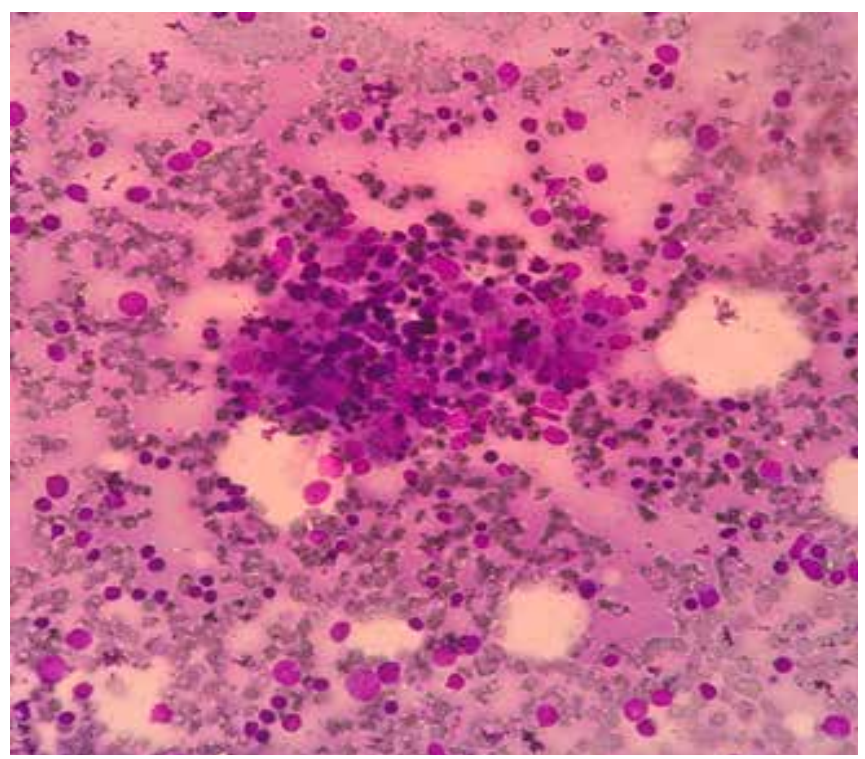


Fig 4: Pleomorpic bizzare cells in case of anaplastic carcinoma of thyroid. (Giemsa 400x)

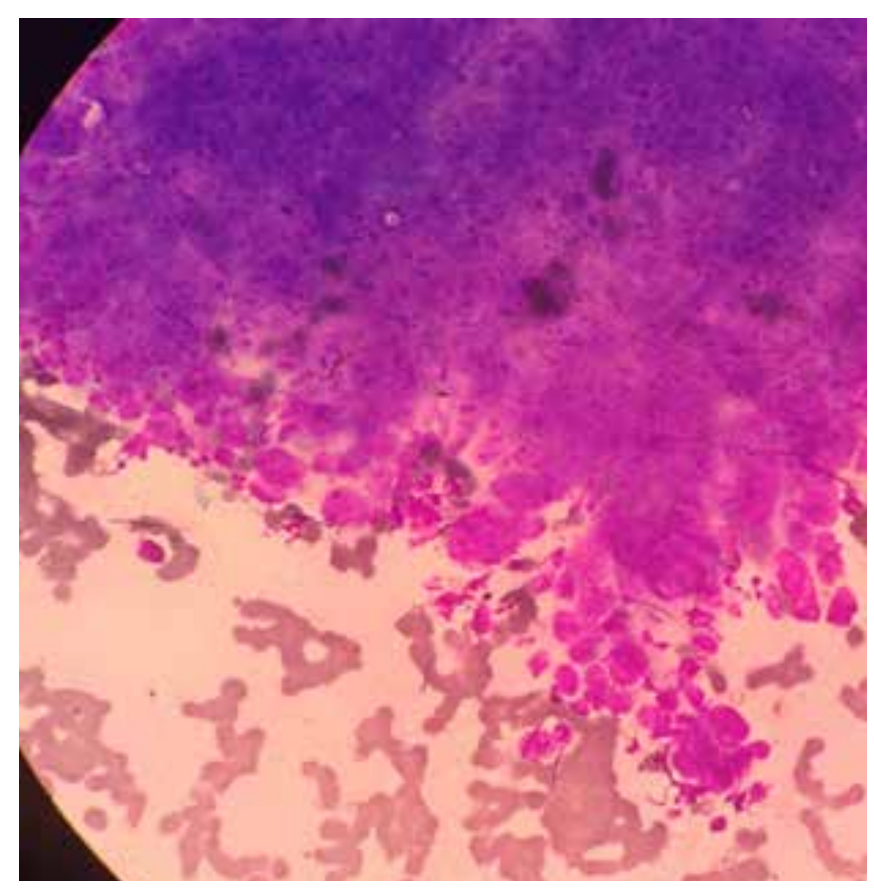

\section{DISCUSSION}

Enlargement of thyroid or goitre are a very common problem encountered in clinical practice and it occurs in $4-10 \%$ of the population ${ }^{5}$. Most of the swellings are benign and frequency of malignancy range from 10 to $20 \% \%^{5,6,7}$. Thyroid enlargement whether benign or malignant, needs thorough investigation mainly to rule out the possibility of malignancy and thyroiditis ${ }^{8}$.

FNAC is a simple and inexpensive procedure done in outpatient department for obtaining diagnosis. This procedure has few complications including the tumor implantation along the needle tract ${ }^{9}$. The recommendation of American Thyroid Association (ATC) (2015) state that for any thyroid nodule $>$ or equal to $2 \mathrm{~cm}$, ultrasound should be the initial investigation followed by FNAC $^{10}$. FNAC along with other investigation like USG, TFT, thyroid scan and antibody level are done aiming to select the patients who require surgery and those who can be managed conservatively ${ }^{11,9}$.

Our present study showed that thyroid lesions are common in females with female to male ratio $9: 1$ which is similar to the study done by Poudel et $a l^{12}$, Yang et $a l^{13}$, Sood et $a l^{14}$, Jaragh et $a l^{15}$, Renshaw et $a l^{16}$ and Junu et $a l^{17}$. In the present study, age of the patient ranged from 8 82 years with the mean age of 44.6 years. This is justified by similar findings stated by Karki et $a l^{18}$ and Staii et $a l^{19}$,. Present study showed most commonly affected age is 41 - 60 years which is comparable to the study done by Junu Devi $e$ t $a l^{17}$ and Poudel et $a l^{12}$.

The study showed that $88 \%$ are non neoplastic lesion and $12 \%$ are neoplastic lesion whereas in study by Junu Devi et $a l^{17}$, Choudhary R et $a l^{3}$ and Chandanwale S et a $l^{20}$ (neoplastic and non neoplastic cases were $4.55 \%$ and $94.95 \%$ respectively. This variation might be due to the sample size.

According to the study done by Siddegowda et $a l^{21}$, Chaudhary R et a ${ }^{3}$, Chandanwale $\mathrm{S}$ et $a^{20}$ and Junu Devi et $a l^{17}$, among the non neoplastic lesion colloid goitre was the common thyroid lesion followed by lymphocytic thyroiditis which had the similarity with the present study.

Among the neoplastic lesion, papillary carcinoma of thyroid is the most common followed by follicular neoplasm which is similar to the study by Junu Devi et $a{ }^{17}$, Chadanwale $\mathrm{S}$ et $a l^{20}$ and Tabaqchali $e t a l^{2}$ but in the study done by Chaudhary S et al ${ }^{22}$ and CK Sang et al follicular lesions were most common (followed by papillary carcinoma).

The cytological analysis was accompanied with the thyroid hormone status as according to the guidelines of ATC, serum estimation of TSH should be part of initial assessment of the thyroid lesion ${ }^{10}$. The etiology of thyroid lesion is different so does the thyroid hormone status differ depending on the stage and extent of the disease. In our study, most of the patients were euthyroid (66\%) which is similar to the study by Siddegowda et $a l^{21}$. This showed while correlating the thyroid disease with hormonal status, most patients with colloid goitre 79\% had euthyroid (66\%) status followed by hypothyroid (22\%) and hyperthyroid (12\%). This finding was similar to a study done by Siddegowda et $a l^{21}$, Junu et $a 1^{17}$ and Chaudhary R et $a{ }^{\beta}$. Goitre is due to the impaired synthesis of thyroid hormone which is most often the result of dietary iodine deficiency leading to increase in the TSH level and this TSH increment stimulates thyroid follicular cells causing compensatory hypertrophy and hyperplasia which finally leads to enlargement of the gland. Goitre leads to increased hormonal level and achievement of euthyroid status in patients ${ }^{23}$.

In patients with Hashimoto's thyroiditis, most of the patients were hypothyroid $80 \%$ which is similar to the 
study done by Minnu Prasannan et $a l^{24}$ and Siddegowda et $a l^{21}$. Hashimoto thyroiditis progress over a period of time to subclinical and then clinically over to hypothyroidism. In some cases, it may be preceded by a transient hyperthyroid state (hashitoxicosis) due to destruction of follicles and subsequent rise in the free $\mathrm{T} 3$ and $\mathrm{T} 4$ along with fall in $\mathrm{TSH}^{23}$. In our study, patient with lymphocytic thyroiditis $50 \%$ were euthyroid followed by $38 \%$ hypothyroid which is similar to the other study by Junu et $a{ }^{17}$ and Baruah RN et $a l^{25}$.This is explained by the fact that generally in six to eight weeks after inflammation subsides, thyroid function returns to normal ${ }^{23,26}$. Cytologically thyroid follicular cells entangled with lymphocytes, oxyphil cells, abundant polymorphous population of lymphocytes, multinucleated giant cells, cant or no colloid were observed in Hashimoto's or lymphocytic thyroiditis.

All the cases of subacute thyroiditis were hyperthyroid in our study which is similar to Junu et $a l^{17}$ and comparable to the study by by Barua RN and Aman $\mathrm{FZ}^{25}$. In this study papillary carcinoma had a biochemical diagnosis of euthyroid which is similar to the study by Junu et $a l^{17}$, Sang CK et $a l^{7}$ and Poudel et $a l^{12}$. Cytologically According to Orell and Sterrett, it is highly suspicious for PTC, if the smears contain nuclear groove in more than $20 \%$ of cells and INCIs in 5\%, but still it is not significant. Besides cellularity, nuclear grooving and INCI, pleomorphism, pattern, nucleoli, foam cells are also statistically significant for the diagnosis of thyroid lesions ${ }^{27}$.

\section{CONCLUSIONS}

Fine needle aspiration cytology (FNAC) is a safe, inexpensive, easy, less time consuming modality for evaluation of different thyroid swellings. FNAC together with thyroid function test (TFT) analysis leads to early and accurate diagnosis of various thyroid diseases and reduces surgical intervention. The study showed that FNA cytologic diagnosis cannot be used to predict thyroid function using total serum T4, T3 and TSH concentrations. Measurement of TSH, free T4, and free T3 would be preferable.

\section{REFERENCES}

1. Agarwal S. Diagnostic accuracy and role of fine needle aspiration cytology in management of thyroid nodules. J Surg Oncol. 1995; 58: 168-72.
2. Tabaqchali MA, Hanson JM, Johnson SJ, Wadehra V, Lennard TW, Proud G. Thyroid aspiration cytology in Newcastle: A six year cytology/ histology correlation study. Ann R Coll Surg Engl. 2000; 82: 149-55.

3. Ritica Chaudhary, Zulfikar Ahmed, Umaru N. "A Correlative study of FNAC thyroid with thyroid hormone profile". Journal of Evolution of Medical and Dental Science. 2014 February 10; 3(6): 1474-1480. DOI: $10.14260 /$ jemds/ 2014/2010.

4. Holleman F, Hoekstra JB, Ruitenberg HM. Evaluation of fine needle aspiration (FNA) cytology in the diagnosis of thyroid nodules. Cytopathol off $\mathrm{J} \mathrm{Br}$ Soc Clin Cytol. 1995 Jun; 6(3): 16875. http://dx.doi. org/10.1111/j.1365-2303.1995.tb00470.x

5. Kumar S, Aquil S, Dahar A. Role of fine needle aspiration cytology in thyroid diseases. Int J Surg. 2008; 13:22-5.

6. Franklyn JA et al. The value of imaging in the diagnosis of thyroid cancer. Nuclear Med Comm 1992; 13: 641-3.

7. Sang CK, Kigondu CS, Muchiri L. Fine needle aspiration cytology of thyroid nodules at Kenyatta National Hospital, Nairobi. East Afr Med J. 2007; 84(3): 117-20

8. Sukant Garg, Uma Handa, Harsh Mohan, Nitin Nagarkar. Role of fine needle aspiration cytology in diagnosis and management of thyroid lesions: A study on 434 patients. Journal of Cytology. Jan - Mar, 2008; 25(1): pp.1317.

9. Monoj Gupta, Savita Gupta, and Ved Bhushan Gupta. Correlation of Fine Needle aspiration Cytology with Histopathology in the Diagnosis of Solitary Thyroid Nodule. Journal of Thyroid Research. 2010; Article ID 379051, 5 pages doi:10.4061/2010/379051

10. Haugen BR, Alexander EK, Bible KC, Doherty GM, Mandel SJ, Nikitorov YE, et al. 2015 American thyroid association management guidelines for adult patients with thyroid nodules and differentiated thyroid cancer. Thyroid. 2016; 26(1): 1-133.

11. Giuffrida D, Gharib H. Controversies in the management of cold, hot, and occult thyroid nodules. Am J Med. 1995 Dec; 99(6): 64250. http://dx.doi. org/10.1016/S0002-9343(99)80252-6

12. Suman Poudel, Sudeep Regmi, Anita Shahi, Ashok Samdurkar. Cytopathological evaluation of thyroid by fine needle aspiration cytology and correlation with 
T3, T4 and TSH levels. Journal of Universal College of Medical Sciences. 2015; 03(04) Issue 12; Page: 37 41.

13. Yang GCH, Stern CM, Messina AV. Cystic papillary thyroid carcinoma in fine needle aspiration may represent a subset of the encapsulated variant in WHO classification. Diagn Cytopathol. 2010 Oct; 38(10): 7216. PMid:20024942

14. Sood N, Nigam JS. Correlation of fine needle aspiration cytology findings with thyroid function test in cases of lymphocytic thyroiditis. J Thyroid Res. 2014; 2014: 430510. http://dx.doi.org/10.1155/2014/430510 PMid:24808970 PMCid:PMC3997907

15. Jaragh M, Carydis VB, MacMillan C, Freeman J, Colgan TJ. Predictors of malignancy in thyroid fine-needle aspirates "cyst fluid only" cases: Can potential clues of malignancy be identified? Cancer. 2009 Oct 25; 117(5): 30510. http://dx.doi.org/10.1002/ cncy. 20041

16. Renshaw AA. Focal features of papillary carcinoma of the thyroid in fine-needle aspiration material are strongly associated with papillary carcinoma at resection. Am J Clin Pathol. 2002 Aug; 118(2): 20810. http://dx.doi.org/10.1309/QDLD-FTY3M8ED-CX6U PMid:12162679

17. Devi J, Aziz N. Cytomorphological evaluation and thyroid function test analysis in various thyroid diseases - our experience at tertiary care centre. International Journal of Medical Science and Clinical Inventions. 2014; 1(8): 387-92. Available at http:// valleyinternational.net/index.php/our-jou/ijmsci

18. Karki S, Shrestha A. Fine needle aspiration cytology of thyroid and its correlation with serological findings. Journal of Pathology of Nepal. 2017; 7: 1054-58. DOI:

\subsection{6/jpn.v7i1.16777}

19. Staii A, Mirocha S, Todorova-koteva $K$, Glinberg S, Jaume JC. Hashimoto thyroiditis is more frequent than expected when diagnosed by cytology which uncovers a pre-clinical state. Thyroid research. 2010; 3: 11 .

20. Chandanwale $S$ et al. Clinicopathological correlation of thyroid nodules. Int J Pharm Biomed 2012; 97-102.

21. M. S. Siddegowda, JaSneet Kaur Sandhu, S. ShivaKuMar. Cytomorphological Assessment and Thyroid Function Analysis - A Dual Approach to Diagnose Thyroid Lesions. National Journal of Laboratory Medicine. 2016 Jul; 5(3): 16-21. DOI: 10.7860/NJLM/2016/20542:2128

22. Chaudhari S, Hatwal D, Bhat P, Batra N, Bhat S. Cytological evaluation of thyroid lesions and its correlation with histopathology: A prospective study. Int J Sci Stud. 2015; 3(8): 132-35.

23. Maitra A. Endocrine system. In: Kumar V, Abbas AK, Fausto N, Astor JC, editors. Robbins and Cotran Pathologic Basis of Disease. 9th ed. Philadelphia: Elsevier; 2014. p.1090-92.

24. Prasannan M, Kumar SA. Hashimoto's thyroiditis-a cytomorphological study with serological correlation. IJSAR. $2015 ; 2(8): 47-52$

25. Baruah RN, Zaman F. Cytomorphological diagnosis of thyroiditis and correlation with thyroid function. Thyroid Research and Practice.

26. Singer P.A. Evaluation and management of the solitary thyroid nodule. Otolaryngol Clin North-Amer. 1996; 29: 577-581

27. Svante R. Orell, Gregory F. Sterrett. Fine Needle Aspiration Cytology. 5th ed. 118-155. 